\title{
Article
}

\section{Resin-Based Cement Applied to Enamel and Dentin Pre-Treated with Phytic Acid: An In Vitro Study}

\author{
Mohannad Nassar ${ }^{1,+}+\mathbb{D}_{\text {, Md }}$. Sofiqul Islam ${ }^{2,+}{ }^{+}$, Smriti Aryal A C ${ }^{3}$, Hatem Mostafa El-Damanhoury ${ }^{1}$, \\ Salvatore Sauro ${ }^{4,5, *(D)}$ and Noriko Hiraishi ${ }^{6}$
}

1 Department of Preventive and Restorative Dentistry, College of Dental Medicine, University of Sharjah, Sharjah 27272, United Arab Emirates; minassar@sharjah.ac.ae (M.N.); hdamanhoury@sharjah.ac.ae (H.M.E.-D.)

2 Operative Dentistry, RAK College of Dental Sciences, RAK Medical and Health Sciences University, Ras Al-Khaimah 30248, United Arab Emirates; sofiqul.islam@rakmhsu.ac.ae

3 Department of Oral and Craniofacial Health Sciences, College of Dental Medicine, University of Sharjah, Sharjah 27272, United Arab Emirates; saryalac@sharjah.ac.ae

4 Dental Biomaterials and Minimally Invasive Dentistry, Departamento de Odontología, Facultad de Ciencias de la Salud, Universidad CEU-Cardenal Herrera, C/Del Pozo s/n, Alfara del Patriarca, 46115 Valencia, Spain

5 Department of Therapeutic Dentistry, Sechenov University of Moscow, 119435 Moscow, Russia

6 Cariology and Operative Dentistry, Graduate School of Medical and Dental Sciences, Tokyo Medical and Dental University, Tokyo 112-0000, Japan; hiraope@tmd.ac.jp

* Correspondence: salvatore.sauro@uchceu.es

+ Nassar and Islam have contributed equally to this work and are considered joint first authors.

check for updates

Citation: Nassar, M.; Islam, M.S.; A C, S.A.; El-Damanhoury, H.M.; Sauro, S.; Hiraishi, N. Resin-Based Cement Applied to Enamel and Dentin Pre-Treated with Phytic Acid: An In Vitro Study. Appl. Sci. 2021, 11, 11976. https://doi.org/10.3390/ app112411976

Academic Editor: Hari Mohan Srivastava

Received: 21 November 2021 Accepted: 12 December 2021 Published: 16 December 2021

Publisher's Note: MDPI stays neutral with regard to jurisdictional claims in published maps and institutional affiliations.

Copyright: (c) 2021 by the authors. Licensee MDPI, Basel, Switzerland. This article is an open access article distributed under the terms and conditions of the Creative Commons Attribution (CC BY) license (https:/ / creativecommons.org/licenses/by/ $4.0 /)$.

\begin{abstract}
Phytic acid (IP6) has the ability to etch tooth structure due to its acidity and chelating properties. This study aimed to evaluate the micro-tensile bond strength ( $\mu$ TBS) of resin-based cement to enamel and dentin using manufacturer-provided etchants, phosphoric acid (PA) for enamel and a mixture of $10 \%$ citric acid and 3\% ferric chloride (CAF) for dentin and compare them to IP6. Enamel surfaces were etched for $30 \mathrm{~s}$ with either PA or IP6 (1\%, $5 \%$ or $10 \%)$. Dentin surfaces were etched for $15 \mathrm{~s}$ with either CAF or 1\% IP6. Pre-polymerized composite blocks were bonded to enamel and dentin surfaces. After $24 \mathrm{~h}$, the specimens were sectioned into beams and subjected to $\mu \mathrm{TBS}$ testing. De-bonded specimens and smear layer removal were analyzed with a scanning electron microscope. Etching enamel with 1\% and 5\% IP6 resulted in $\mu$ TBS values that are comparable to the control (PA) $(p>0.05)$, while $10 \%$ IP6 negatively affected the $\mu$ TBS $(p<0.05)$. The $\mu$ TBS to dentin etched with $1 \%$ IP6 was higher compared to the control (CAF) $(p=0.001)$. IP6 effectively removed enamel and dentin smear layer, and at specific concentrations, it may be a suitable alternative conditioner agent for bonding resin-based cement to enamel and dentin.
\end{abstract}

Keywords: phytic acid; resin-based cement; bond strength; dentin; enamel; smear layer; IP6; phosphoric acid

\section{Introduction}

Adhesive resin cements are often favored over conventional luting cements because of their valuable mechanical properties [1]. Moreover, resin-based adhesive cements are frequently used in dentistry for luting procedures involving prostheses and orthodontic appliances thanks to their ability to bond to enamel, dentin, metal, resin and porcelain [2]. It has also been reported that such resin systems have excellent tolerance of dentin contamination with water, saliva, and blood [3], as well as high biocompatibility with pulpal tissue [4]. Super-Bond C\&B (Sun Medical Co. Ltd., Moriyama, Japan) was introduced in 1983 for general dental adhesive use. Although the monomer and polymer are identical for both enamel and dentin bonding, the dentin conditioner is different to the enamel etching solution in the aforementioned resin cement system. Indeed, the enamel etchant is composed of phosphoric acid (PA) and the dentin conditioner is made of a mixture of $10 \%$ 
citric acid and 3\% ferric chloride (CAF) [5]. Previous studies reported that the application of a $10 \%$ citric acid and $3 \%$ ferric chloride solution for dentin etching contributes to high bond strength to dentin [6] and excellent clinical retention rates for methacrylate-based adhesives [7]. Some 4-META-based self-etching adhesive resin cements (such as M-Bond, M-Bond II by Tokuyama Dental) have been introduced with the ability to etch both enamel and dentin simultaneously. Despite these advantages offered by such materials, there are several concerns regarding bond durability to dentin [8].

Phytic acid, which is also known as inositol hexa-phosphate (IP6), can be extracted from various plant seeds [9]. IP6 possesses a strong negative charge [10], which can chelate the positively charged cations and precipitate in the form of a complex salt at neutral $\mathrm{pH}$ [11], but soluble in acidic conditions. An initial interest in IP6 employed in dentistry started several decades ago with the identification of its cariostatic, anti-calculus and antiplaque ability, as well as to its cement-forming properties and its ability to reduce enamel dissolution [12-15]. However, it is only recently that such interest in IP6 has increased with the exploration of new applications in endodontics [16-20] and adhesive dentistry [21-23]. In 2013, IP6 was proposed as an effective etchant, which resulted in higher bond strength to dentin and a lower cytotoxic effect on pulpal cells when compared to PA [21].

To the best of our knowledge and in view of the most recent available literature, there is little information about the effect of IP6 on etching and bonding to enamel and its effect on the adhesion of resin-based cement to dentin. Thus, the aim of this study was to evaluate the micro-tensile bond strength ( $\mu$ TBS) of resin-based cement to enamel and dentin using IP6 prior to bonding and compare it to that of conventional agents provided by the manufacturer of PA for enamel and CAF for dentin. The null hypotheses tested were (1) there would be no difference between the bond strength of the resin-based cement applied on enamel etched using the manufacturer-provided agents (PA) or the different concentrations of IP6 and, (2) there would be no difference between the bond strength of the MMA-based resin cement to manufacturer-provided (CAF) or IP6-etched dentin.

\section{Materials and Methods}

\subsection{Preparation of Composite Block}

Composite specimens were prepared using the composite blocks ESTENIA C\&B (Kuraray Noritake Dental Inc., Tokyo, Japan). These were light-cured for $30 \mathrm{~s}$ from the top using a visible light-curing unit (OPTILUX 501, Kerr Corporation, CA, USA), with a light intensity of $650 \mathrm{~mW} / \mathrm{cm}^{2}$. The blocks were additionally light-cured for $5 \mathrm{~min}$ in the chamber of a visible light-curing unit (Alpha-Light II Morita Corp., Osaka, Japan). According to the manufacturer's instructions, the blocks were further heat-cured in a specific oven at a temperature of $100{ }^{\circ} \mathrm{C}$ for $15 \mathrm{~min}$ (KL-100, Kuraray Noritake Dental Inc., Tokyo, Japan). The blocks were then etched with $37 \%$ phosphoric acid (Scotch bond Etchant; 3M ESPE, St Paul, MN, USA) for $15 \mathrm{~s}$. After washing with an air/water spray, the blocks were air-dried and immediately primed with a mixture of Clearfil SE Bond primer (Kuraray Noritake Dental Inc., Tokyo, Japan) and Clearfil porcelain bond activator (Kuraray Noritake Dental Inc., Tokyo, Japan) at a 1:1 ratio for $5 \mathrm{~s}$ then gently air-dried.

\subsection{Tooth Preparation}

Sixteen freshly extracted non-carious human molars were collected and used in this study. The buccal and lingual surfaces of the enamel were ground flat using a \#600 SiC paper under water irrigation to create a smear layer on the enamel surfaces. A flat occlusal dentine surface was created using a slow-speed diamond saw (Isomet, Buehler, Ltd., Lake Bluff, IL, USA), under water cooling. A standard smear layer was produced on each surface using \#600 SiC paper under water irrigation. The enamel surfaces were etched either with the manufacturer-provided enamel etchant (65\% PA) for 30 s or 1\%, 5\% or 10\% IP6 (Wako Pure Chemical Industries, Osaka, Japan) for $30 \mathrm{~s}$. The dentin surfaces were treated either 
with the manufacturer-provided dentin conditioner (CAF) for $15 \mathrm{~s}$ or by using $1 \%$ IP6 for $15 \mathrm{~s}$. Then, the specimens were thoroughly rinsed with distilled water spray and air-dried.

\subsection{Adhesive Procedures on Dental Substrates}

The etched enamel and dentin surfaces were luted by priming composite blocks using an adhesive resin cement system (Super Bond C\&B, Sun Medical Co. Ltd., Moriyama, Japan) as per the manufacturer's instructions. A PMMA powder was soaked in the mixture of monomer and catalyst (4:1) with an applicator brush provided by the manufacturer and applied on the etched surfaces as well as on the composite blocks. The composite blocks and tooth surfaces were then kept together in close contact under a constant gentle pressure (50 gr) and allowed to set for $10 \mathrm{~min}$. Subsequently, the specimens were stored in distilled water at $37^{\circ} \mathrm{C}$ for $24 \mathrm{~h}$.

\subsection{Micro-Tensile Bond Strength Testing}

After water storage $(24 \mathrm{~h})$, the specimens were sectioned to obtain composite-enamel or composite-dentin beams $(0.9 \mathrm{~mm} \times 0.9 \mathrm{~mm})$ using a slow-speed diamond saw (Isomet, Buehler, Ltd., Lake Bluff, IL, USA), under water cooling. The exact dimensions of each beam were measured using a digital caliper (Fisherbrand ${ }^{\mathrm{TM}}$ Traceable ${ }^{\mathrm{TM}}$ Digital Calipers; Fisher Scientific, Hampton, NH, USA), and the beams were then glued to the test apparatus using a cyanoacrylate superglue (Model Repair II Blue, Dentsply-Sankin, Ohtawara, Japan) and stressed to failure under micro-tension using a universal testing machine (EZ Test, Shimadzu Co., Kyoto, Japan) at a crosshead speed of $1 \mathrm{~mm} / \mathrm{min}$.

\subsection{Failure Mode Analysis}

The fractured enamel and dentin surfaces were air-dried, sputter-coated with gold/palladium and examined using a scanning electron microscope (SEM, JSM-5310LV scanning microscope, JEOL, Ltd., Tokyo, Japan) operating at $15 \mathrm{kV}$. The failure modes were classified into three types: (I) adhesive failure to composite, (II) cohesive failure within the luting cement and (III) adhesive failure to enamel or dentin substrate.

\subsection{SEM Analysis of the Etching Effect on Enamel and Dentin Smear Layer}

To examine the effect of the etchants and conditioning agents on the enamel and the dentin smear layer, enamel, and dentin discs of approximately $1 \mathrm{~mm}$ thickness were obtained from extracted human molar teeth. The enamel surfaces were treated either with the manufacturer-provided enamel etchant (PA) or one of $1 \%, 5 \%$ and $10 \%$ IP6 for $30 \mathrm{~s}$. The dentin surfaces were treated either with manufacturer-provided dentin etchant (CAF) or $1 \%$ IP6 for $15 \mathrm{~s}$. After treatment, the discs were washed with water spray and air-dried, dehydrated in ascending ethanol concentrations and immersed in hexamethyldisilazane (Wako Pure Chemical Industries, Osaka, Japan) for $10 \mathrm{~min}$. Finally, the specimens were mounted on aluminum stubs, sputter-coated with gold/palladium and examined with the SEM operating at $15 \mathrm{kV}$.

\section{Results}

\subsection{Micro Tensile Bond Strength}

The results of the $\mu$ TBS test to enamel and dentin are shown in Figure 1a,b, respectively. One-way ANOVA showed significant differences among the tested groups for enamel $\mu$ TBS. A Tukey post hoc test revealed no significant differences in $\mu$ TBS to enamel of $1 \%$ IP6 $(37.9 \pm 6 \mathrm{MPa})$ and 5\% IP6 $(38.9 \pm 5.8 \mathrm{MPa})$ groups compared to the control group (PA) (38.9 \pm 7.2$)(p>0.05)$. The $\mu$ TBS value significantly reduced with the use of $10 \%$ IP6 (34.8 $\pm 6.4 \mathrm{MPa})$ compared to the control group (PA) $(p=0.01)$. The individual $T$-test revealed that the $\mu$ TBS to dentin of $1 \%$ IP6 (31.3 \pm 5.4$)$ was significantly higher than the control group $(\mathrm{CAF})(25.7 \pm 5.6)(p=0.001)$. 

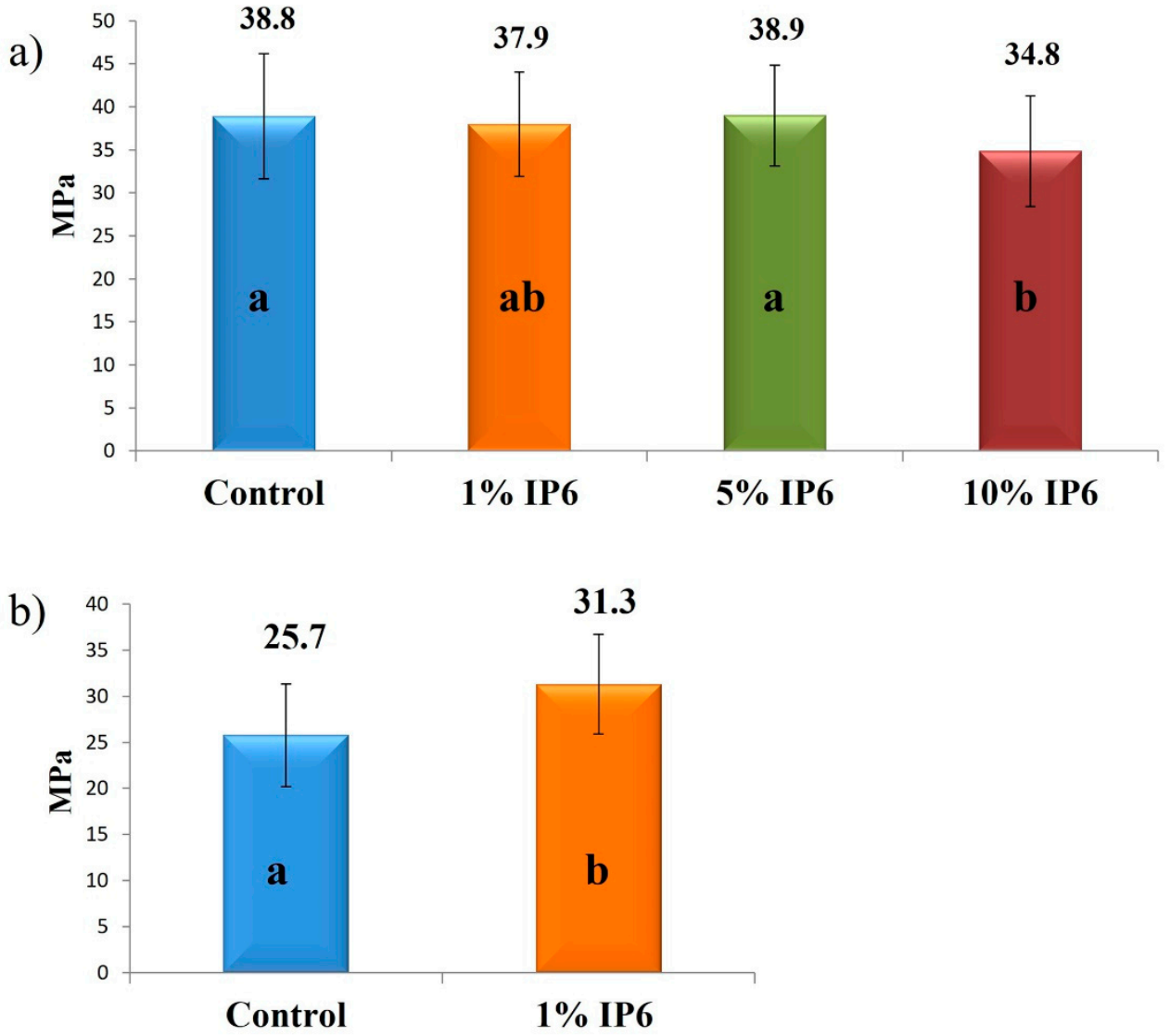

Figure 1. (a) Micro tensile bond strength to enamel after $24 \mathrm{~h}$ water storage, control group (PA) $(38.9 \pm 7.2 \mathrm{MPa}), 1 \%$ IP6 group (37.9 $\pm 6 \mathrm{MPa}), 5 \%$ IP6 group (38.9 $\pm 5.8 \mathrm{MPa})$ and 10\% IP6 group $(34.8 \pm 6.4 \mathrm{MPa})$. (b) Micro tensile bond strength to dentin after $24 \mathrm{~h}$ water storage, control group (CAF) $(25.7 \pm 5.6 \mathrm{MPa}), 1 \%$ IP6 group $(31.3 \pm 5.4 \mathrm{MPa})$. Groups with the same lower-case letter designations are not statistically significant $(p>0.05)$.

\subsection{Failure Mode}

The results of the fracture patterns and percentage of failure modes of de-bonded enamel and dentin specimens are shown in Figures 2 and 3, respectively. For enamel specimens (Figures $2 a-d$ and $3 a$ ), most of the specimens failed in adhesive mode failure regardless of the experimental group. For dentin specimens (Figure 2e,f and Figure $3 b$ ), the control group (CAF) showed a higher percentage of adhesive failure to dentin compared to the specimens that received IP6 treatment. 

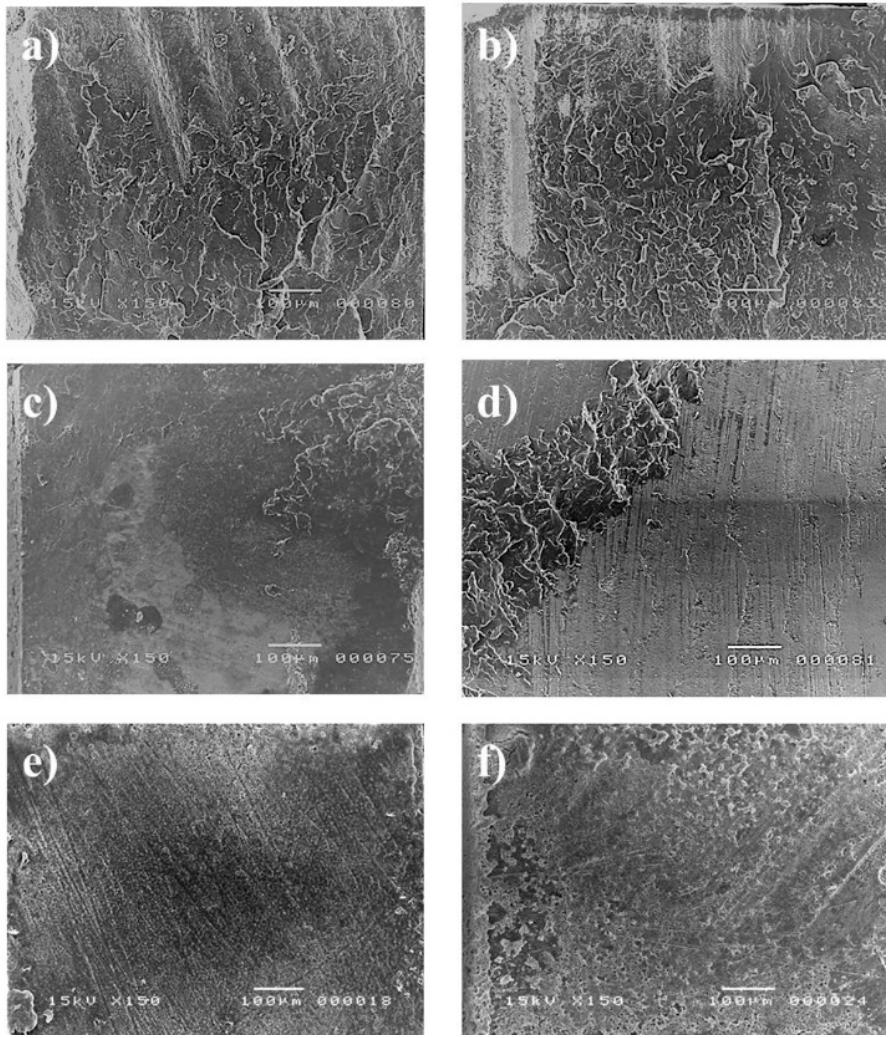

Figure 2. Representative SEM images of fractured enamel surfaces: (a) control group (PA); (b) 1\% IP6 group; (c) 5\% IP6 group; (d) 10\% IP6 group; and representative SEM images of fractured dentin surfaces: (e) control group (CAF); (f) 1\% IP6 group.

a)

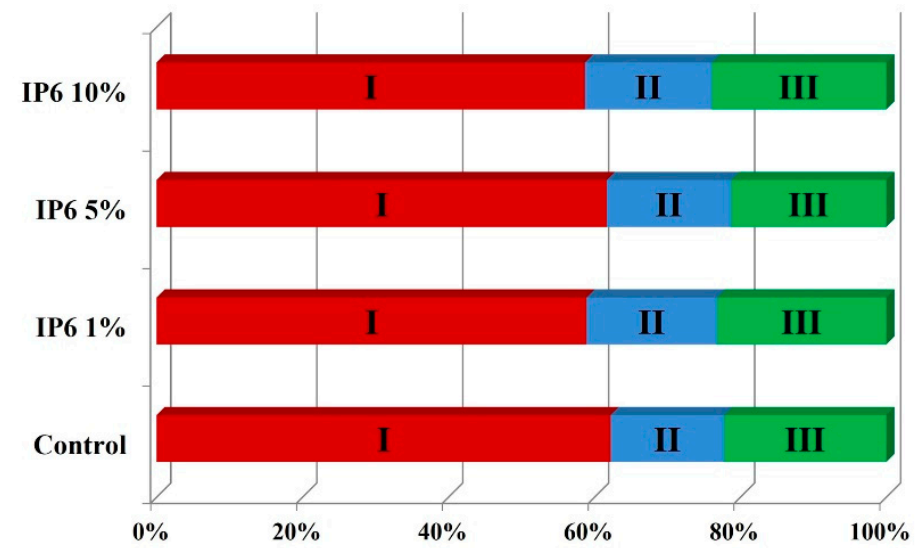

b)

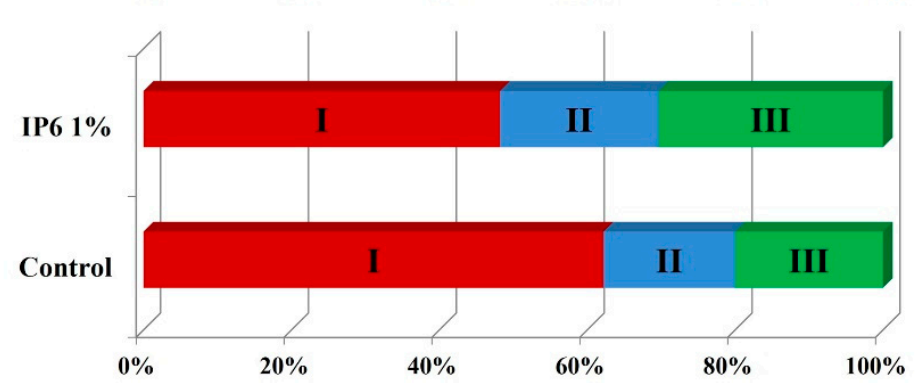

Figure 3. (a) Location and failure percentage of enamel side of fractured specimens during bond strength measurement. (b) Location and failure percentage of dentin side of fractured specimens during bond strength measurement. (I) Adhesive failure to composite, (II) cohesive failure within the luting cement and (III) adhesive failure to enamel or dentin substrate. 


\subsection{Effect of Etchant on Smear Layer Removal}

The SEM observation showed that both control (PA) (Figure 4a) and IP6 (1\%, 5\%, 10\%) (Figure $4 \mathrm{~b}-\mathrm{d}$ ) could remove the smear layer created on enamel by the use of \#600 grit paper. The manufacturer's dentin etchant (CAF) (Figure 4e) and 1\% IP6 (Figure 4f) showed a similar etching pattern in dentin groups, with complete smear layer removal and open dentinal tubules.
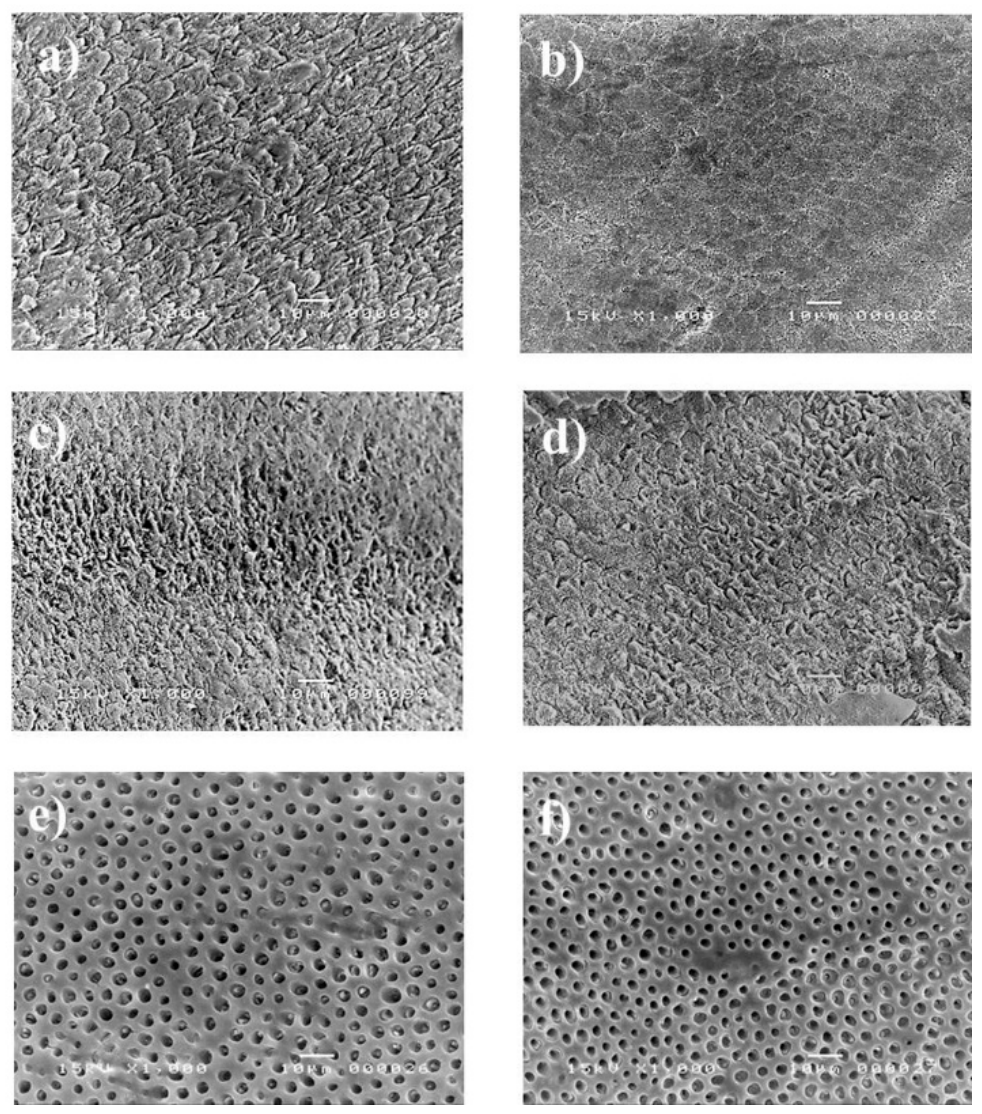

Figure 4. SEM images of enamel smear layer removal: (a) control group (PA); (b) 1\% IP6 group; (c) 5\% IP6 group; (d) 10\% IP6 group; and SEM images of dentin smear layer removal; (e) control group (CAF); (f) $1 \%$ IP6 group.

\section{Discussion}

The effect of manufacturer-provided etchants (PA or CAF) and IP6 etchant on the immediate bond strength of the resin-based cement to enamel and dentin were addressed in the current study. The results showed that the manufacturer-provided etchant (PA) had no significant difference compared to $1 \%$ and $5 \%$ IP6, but superior performance than $10 \%$ IP6 when bonded to enamel. Thus, the first null hypothesis that the different concentrations of IP6 would not affect the bond strength of the resin-based cement to enamel compared to manufacturer-provided etchants (PA) must be partially rejected. On the other hand, the manufacturer-provided dentin etchant (CAF) showed lower bonding performance than $1 \%$ IP6 to dentin; the second null hypothesis must be rejected.

The peculiar structure and the high-density negative charges of IP6 confer a great chelation and unique antioxidant abilities, making it suitable for several applications in dentistry. Despite the compelling data on the merits of IP6 use in dentistry, only very few studies have tested its effect on the bonding of dental adhesive systems to enamel and dentin [24]. We chose to use IP6 in a concentration of $1 \%$ on dentin and not higher, based on our pilot study results, where the higher concentrations resulted in an aggressive etching pattern on dentin which negatively affected adhesion (data are not shown). In this study, IP6 has been proven to be an effective agent for removing the smear layer 
from enamel and dentin; this effect is mainly attributed to its acidity and ability to chelate with calcium. The higher bond strength to dentin obtained with the use of IP6 might be explained by several mechanisms. Firstly, we hypothesize that the IP6 is able to form insoluble complexes with calcium at $\mathrm{pH}$ higher than 4 [25]. Despite the low acidity of IP6, these complexes are expected to occur upon conditioning with IP6 due to the high buffering capacity of dentin [26]. The insoluble IP6-calcium complexes might provide structural stability to the exposed dentinal collagen network thus enhancing monomer infiltration and bonding to dentin. The stability of collagen is also enhanced by a binary or ternary interaction of IP6 with collagen as described hereafter. IP6 is reported to have a crosslinking effect on collagen, through an electrostatic interaction that results in a binary association between the negatively charged IP6 and the dentinal collagen network that might attain a positive net charge upon exposure to acids $[27,28]$. A ternary interaction might also occur between IP6 and collagen where a cation such as calcium bridges IP6 to collagen. This type of interaction occurs at a $\mathrm{pH}$ above the isoelectric point of collagen. A less understood mechanism of IP6-induced stabilization of collagen is called the kosmotropic effect where IP6 acts as a Hofmeister anion through its six anionic groups by interacting with water in the surrounding medium [27]. It has been recently demonstrated that the treatment of dentin with IP6 resulted in less total dentinal collagen degradation compared to phosphoric acid [29]. In the present study, the decreased percentage of adhesive failures to dentin in the IP6-treated group might be a reflection of the enhanced stability of the exposed collagen network by the action of IP6.

Despite the developments in the strategies of bonding to enamel, acid-etching of enamel is still the gold standard procedure for effective enamel bonding through the demineralization of the surface forming a microporous layer with a high surface energy in which the resin infiltrates, forming resin tags [30]. However, the length of these tags has minimal impact on the bond strength values [31]. PA acid is known to create a hydroxyapatitedenuded and fragile dentinal collagen network that is susceptible to collapse upon drying and to degradation by the action of proteinases [32]; this results in suboptimal bonding to dentin [33]. Due to the aggressiveness of PA on dentin, there has been a shift from total etch technique to selective etch technique which requires the use of a separate etching step to be applied only on the enamel, leaving the dentin surface untouched by the action of the acid [34]. Most of the restorative procedures include both enamel and dentin, thus, the introduction of an acid that be applied safely on both enamel and dentin would overcome the aforementioned drawbacks of PA. In our study, etching enamel with $1 \%$ and $5 \%$ IP6 showed no superior effect compared to etching procedures performed with the manufacturer etchant (PA), while 10\% IP6 reduced the bond strength of the resin cement to enamel. Although the mechanism is not clear, we speculate that the absence of collagen in enamel [35] makes this substrate unable to take advantage of the ability of IP6 to crosslink with collagen, which is one of the key factors in improving bonding to dentin. Though an ideal etch pattern is not essential to produce high bond strength to enamel [36,37], excessive etching whether by increasing the concentration or the application of time of the etchant would result in compromised bonding to enamel as a result of decreased hardness of this substrate $[38,39]$. IP6 is a stronger acid compared to phosphoric acid and has six phosphate groups with two dissociable $\mathrm{OH}$ groups in each phosphate [39]. Thus, we believe that $10 \%$ IP6 reduced the bond strength by excessively demineralizing and reducing the hardness of the enamel. The etching patterns reported in our study show differences between PA and IP6. Moreover, 1\% IP6 resulted in a clearly less eroded enamel surface compared to the surfaces obtained using $5 \%$ or $10 \%$ IP6 or PA. The clinical relevance, if any, of the different etching patterns is not well understood, however, they are essential for a better understanding of the fundamentals of adhesion [30]. In view of this, future studies should be directed toward in-depth analysis and comparison between these two acids in terms of their effects on the chemical and physical properties of enamel and the bonding quality including its effect on microleakage under different conditions that simulate clinical situations [40]. 


\section{Conclusions}

The limitations of this study include, but are not limited to, the utilization of extracted human teeth from different subjects and the use of in vitro experimental conditions which contribute to only limited answers to more complex problems. Within these limitations, it is possible to affirm that IP6 can effectively etch enamel and dentin simultaneously and remove smear layer from these substrates. Compared to the control etchants provided by the manufacturer (PA for enamel and CAF for dentin), 1\% and 5\% IP6 exhibited similar bond strength of the resin-based cement to enamel and 1\% IP6 resulted in superior bond strength to dentin, while 10\% IP6 resulted in a bond strength value to enamel that is lower than the control. Considering the great interest that IP6 has generated so far in research and since the findings on its potential use as an etchant, further studies must be performed both in vitro and in vivo to confirm such effects on the bonding performance on enamel and dentin, as well as to determine the optimal concentration and application time when applied to tooth structure.

Author Contributions: Conceptualization, M.S.I. and M.N.; methodology, M.S.I. and M.N.; software, M.S.I. and M.N.; validation, N.H. and S.S.; formal analysis, S.A.A.C. and H.M.E.-D.; investigation, M.N. and M.S.I.; resources, N.H., M.S.I. and M.N.; data curation, M.S.I. and M.N.; writing-original draft preparation, M.S.I. and M.N.; writing—review and editing, M.N., S.S., H.M.E.-D. and S.A.A.C.; visualization, M.N. and M.S.I.; supervision, M.S.I. and M.N.; project administration, N.H., M.S.I. and M.N. All authors have read and agreed to the published version of the manuscript.

Funding: This research received no external funding.

Conflicts of Interest: The authors declare no conflict of interest.

\section{References}

1. Umino, A.; Nikaido, T.; Tsuchiya, S.; Foxton, R.M.; Tagami, J. Confocal laser scanning microscopic observations of secondary caries inhibition around different types of luting cements. Am. J. Dent. 2005, 18, 245-250.

2. Nakabayashi, N.; Kojima, K.; Masuhara, E. The promotion of adhesion by the infiltration of monomers into tooth substrates. J. Biomed. Mater. Res. 1982, 16, 265-273. [CrossRef] [PubMed]

3. Itoh, T.; Fukushima, T.; Inoue, Y.; Arita, S.; Miyazaki, K. Effect of water, saliva and blood contamination on bonding of metal brackets with a 4-META/MMA/TBB resin to etched enamel. Am. J. Dent. 1999, 12, 299-304. [PubMed]

4. Shimada, Y.; Seki, Y.; Uzzaman, M.A.; Sattabanasuk, V.; Sasafuchi, Y.; Foxton, R.M.; Otsuki, M.; Tagami, J. Monkey pulpal response to an MMA-based resin cement as adhesive luting for indirect restorations. J. Adhes. Dent. 2005, 7, 247-251. [PubMed]

5. Coli, P.; Brännström, M. The marginal adaptation of four different bonding agents in Class II composite resin restorations applied in bulk or in two increments. Quintessence Int. 1993, 24, 583-591. [PubMed]

6. Nakabayashi, N.; Nakamura, M.; Yasuda, N. Hybrid Layer as a Dentin-Bonding Mechanism. J. Esthet. Restor. Dent. 1991, 3, 133-138. [CrossRef]

7. Takayuki, H.; Yoshizo, M.; Atsushi, M.; Hajime, M.; Emilio, S.H.; Bart, V.M.; Hirofumi, Y.; Takuo, K. A 15-year clinical comparative study of the cumulative survival rate of cast metal core and resin core restorations luted with adhesive resin cement. Int. J. Prosthodont. 2010, 23, 379-405.

8. Nurrohman, H.; Nikaido, T.; Takagaki, T.; Sadr, A.; Waidyasekera, K.; Kitayama, S.; Ikeda, M.; Tagami, J. Dentin bonding performance and ability of four MMA-based adhesive resins to prevent demineralization along the hybrid layer. J. Adhes. Dent. 2012, 14, 339-348. [CrossRef]

9. Kuwano, M.; Mimura, T.; Takaiwa, F.; Yoshida, K.T. Generation of stable “low phytic acid” transgenic rice through antisense repression of the 1D-myo-inositol 3-phosphate synthase gene (RINO1) using the 18-kDa oleosin promoter. Plant Biotechnol. J. 2009, 7, 96-105. [CrossRef]

10. Barrientos, L.G.; Murthy, P.P.N. Conformational studies of myo-inositol phosphates. Carbohydr. Res. 1996, 296, 39-54. [CrossRef]

11. Schlemmer, U.; Frølich, W.; Prieto, R.M.; Grases, F. Phytate in foods and significance for humans: Food sources, intake, processing, bioavailability, protective role and analysis. Mol. Nutr. Food Res. 2009, 53, S330-S375. [CrossRef] [PubMed]

12. Borggreven, J.M.P.M.; Driessens, F.C.M. Effect of phytate and hexadecylamine on the permeability of bovine dental enamel. Arch. Oral Biol. 1983, 28, 375-379. [CrossRef]

13. Nordbö, H.; Rölla, G. Desorption of Salivary Proteins from Hydroxyapatite by Phytic Acid and Glycerophosphate and the Plaque-Inhibiting Effect of the Two Compounds In Vivo. J. Dent. Res. 1972, 51, 800-802. [CrossRef] [PubMed]

14. Grases, F.; Perelló, J.; Sanchis, P.; Isern, B.; Prieto, R.M.; Costa-Bauzá, A.; Santiago, C.; Ferragut, M.L.; Frontera, G. Anticalculus effect of a triclosan mouthwash containing phytate: A double-blind, randomized, three-period crossover trial. J. Periodontal Res. 2009, 44, 616-621. [CrossRef] 
15. Prosser, H.J.; Brant, P.J.; Scott, R.P.; Wilson, A.D. The Cement-forming Properties of Phytic Acid. J. Dent. Res. 1983, 62, 598-600. [CrossRef]

16. Nassar, M.; Hiraishi, N.; Tamura, Y.; Otsuki, M.; Aoki, K.; Tagami, J. Phytic acid: An alternative root canal chelating agent. J. Endod. 2015, 41, 242-247. [CrossRef]

17. Nassar, M.; Hiraishi, N.; Islam, M.S.; Romero, M.J.; Otsuki, M.; Tagami, J. Effect of phytic acid as an endodontic chelator on resin adhesion to sodium hypochlorite-treated dentin. Restor. Dent. Endod. 2020, 45, e44. [CrossRef]

18. Nassar, R.; Nassar, M.; Vianna, M.E.; Naidoo, N.; Alqutami, F.; Kaklamanos, E.G.; Senok, A.; Williams, D. Antimicrobial activity of phytic acid: An emerging agent in endodontics. Front. Cell Infect. Microbiol. 2021, 11, 753649. [CrossRef]

19. Muana, H.L.; Nassar, M.; Dargham, A.; Hiraishi, N.; Tagami, J. Effect of smear layer removal agents on the microhardness and roughness of radicular dentin. Saudi Dent. J. 2021, 33, 661-665. [CrossRef]

20. Nassar, R.I.; Nassar, M. Antimicrobial effect of phytic acid on Enterococcus faecalis. Int. Arab. J. Antimicrob. Agents 2017, 6, 1-7. [CrossRef]

21. Nassar, M.; Hiraishi, N.; Islam, M.S.; Aizawa, M.; Tamura, Y.; Otsuki, M.; Kasugai, S.; Ohya, K.; Tagami, J. Effect of phytic acid used as etchant on bond strength, smear layer, and pulpal cells. Eur. J. Oral Sci. 2013, 121, 482-487. [CrossRef]

22. Kong, K.; Islam, M.S.; Nassar, M.; Hiraishi, N.; Otsuki, M.; Yiu, C.K.Y.; Tagami, J. Effect of phytic acid etchant on the structural stability of demineralized dentine and dentine bonding. J. Mech. Behav. Biomed. Mater. 2015, 48, 145-152. [CrossRef] [PubMed]

23. Kong, K.; Hiraishi, N.; Nassar, M.; Otsuki, M.; Yiu, C.K.Y.; Tagami, J. Effect of phytic acid etchant on resin-dentin bonding: Monomer penetration and stability of dentin collagen. J. Prosthodont. Res. 2017, 61, 251-258. [CrossRef] [PubMed]

24. Nassar, M.; Nassar, R.; Maki, H.; Al-Yagoob, A.; Hachim, M.; Senok, A.; Williams, D.; Hiraishi, N. Phytic Acid: Properties and Potential Applications in Dentistry. Front. Mater. 2021, 8, 638909. [CrossRef]

25. Grynspan, F.; Cheryan, M. Calcium phytate: Effect of ph and molar ratio on in vitro solubility. J. Am. Oil Chem. Soc. 1983, 60, 1761-1764. [CrossRef]

26. Camps, J.; Pashley, D.H. Buffering action of human dentin in vitro. J. Adhes. Dent. 2000, 2, 39-50.

27. Selle, P.H.; Cowieson, A.J.; Cowieson, N.P.; Ravindran, V. Protein-phytate interactions in pig and poultry nutrition: A reappraisal. Nutr. Res. Rev. 2012, 25, 1-17. [CrossRef]

28. Nezu, T.; Winnik, F.M. Interaction of water-soluble collagen with poly(acrylic acid). Biomaterials 2000, 21, 415-419. [CrossRef]

29. Forgione, D.; Nassar, M.; Seseogullari-Dirihan, R.; Thitthaweerat, S.; Tezvergil-Mutluay, A. The effect of phytic acid on enzymatic degradation of dentin. Eur. J. Oral Sci. 2021, 129, e12771. [CrossRef]

30. Lopes, G.C.; Thys, D.G.; Klaus, P.; Oliveira, G.M.S.; Widmer, N. Enamel acid etching: A review. Compend. Contin. Educ. Dent. 2007, 28, 18-24.

31. Shinchi, M.J.; Soma, K.; Nakabayashi, N. The effect of phosphoric acid concentration on resin tag length and bond strength of a photo-cured resin to acid-etched enamel. Dent. Mater. 2000, 16, 324-329. [CrossRef]

32. Pashley, D.H.; Tay, F.R.; Yiu, C.; Hashimoto, M.; Breschi, L.; Carvalho, R.M.; Ito, S. Collagen degradation by host-derived enzymes during aging. J. Dent. Res. 2004, 83, 216-221. [CrossRef] [PubMed]

33. Sauro, S.; Toledano, M.; Aguilera, F.S.; Mannocci, F.; Pashley, D.H.; Tay, F.R.; Watson, T.F.; Osorio, R. Resin-dentin bonds to EDTA-treated vs. acid-etched dentin using ethanol wet-bonding. Dent. Mater. 2010, 26, 368-379. [CrossRef]

34. Frankenberger, R.; Lohbauer, U.; Roggendorf, M.J.; Naumann, M.; Taschner, M. Selective enamel etching reconsidered: Better than etch-and-rinse and self-etch? J. Adhes. Dent. 2008, 10, 339-344.

35. Nanci, A. Enamel: Composition, Formation, and Structure. Ten Cate's Oral Histology; Elsevier: Amsterdam, The Netherlands, 2017; pp. 288-369.

36. Hobson, R.S.; McCabe, J.F. Relationship between enamel etch characteristics and resin-enamel bond strength. Br. Dent. J. 2002, 192, 463-468. [CrossRef] [PubMed]

37. Feitosa, V.P.; Sauro, S.; Ogliari, F.A.; Ogliari, A.O.; Yoshihara, K.; Zanchi, C.H.; Correr-Sobrinho, L.; Sinhoreti, M.A.; Correr, A.B.; Watson, T.F.; et al. Impact of hydrophilicity and length of spacer chains on the bonding of functional monomers. Dent. Mater. 2014, 30, e317-e323. [CrossRef]

38. Zafar, M.S.; Ahmed, N. The effects of acid etching time on surface mechanical properties of dental hard tissues. Dent. Mater. J. 2015. [CrossRef]

39. Gu, M.; Lv, L.; He, X.; Li, W.; Guo, L. Effect of phosphoric acid concentration used for etching on the microtensile bond strength to fluorotic teeth. Medicine 2018, 97, e12093. [CrossRef]

40. Trzcionka, A.; Narbutaite, R.; Pranckeviciene, A.; Maskeliūnas, R.; Damaševičius, R.; Narvydas, G.; Połap, D.; Mocny-Pachońska, K.; Wozniak, M.; Tanasiewicz, M. In vitro analysis of quality of dental adhesive bond systems applied in various conditions. Coatings 2020, 10, 891. [CrossRef] 